\title{
REVITALISASI PENDIDIKAN KEJURUAN AGRIBISNIS PENGOLAHAN HASIL PERTANIAN MELALUI PENGEMBANGAN KURIKULUM BERBASIS INDUSTRI, TEACHING FACTORY DAN SERTIFIKASI KOMPETENSI
}

Revitalization of Vocational Education Agribusiness Processing of Agriculture Products Through the Development of Industry-Based Curriculum, Teaching Factory and Certification

\author{
Sahirman* \\ Widyaiswara Pada Pusat Pengembangan dan Pemberdayaan Pendidik dan Tenaga Kependidikan Pertanian \\ Cianjur Jalan Jangari Km 14 Sukajadi Karang Tengah Cianjur. 43202.
}

Diterima 21 Januari 2018 / Disetujui 04 Februari 2019

\begin{abstract}
ABSTRAK
Pada tanggal 31 Desember 2015 Indonesia mulai memasuki era Masyarakat Ekonomi ASEAN (MEA). Pada hakekatnya tujuan dibentuknya MEA adalah untuk meningkatkan stabilitas perekonomian di kawasan ASEAN, serta diharapkan mampu mengatasi masalah-masalah di bidang ekonomi antar negara ASEAN. Konsekuensi atas kesepakatan MEA adalah terjadinya arus bebas barang dan jasa, arus bebas modal dan investasi, dan arus bebas tenaga kerja terampil bagi negara-negara ASEAN. Arus bebas tenaga kerja dipandang sebagai ancaman sekaligus sebagai peluang bagi negara Indonesia. Oleh karenanya Pemerintah Indonesia melalui Kementerian Pendidikan dan Kebudayaan khususnya Direktorat Pendidikan Menengah Kejuruan menerapkan kebijakan yang dikenal sebagai strategi implementasi revitalisasi SMK. Tujuan Revitalisasi SMK adalah untuk memujudkan link and Match sekolah dengan Dunia Usaha/Industri (DuDi) sehingga menghilangkan kesenjangan antara pendidikan kejuruan dengan kebutuhan DuDi. Tiga kegiatan penting dalam strategi implementasi revitalisasi SMK adalah pengembangan kurikulum berbasis industri, teaching factory, dan sertifikasi kompetensi lulusan. Kegiatan diberlakukan pada berbagai progam keahlian salah satunya adalah program keahlian Agribisnis Pengolahan Hasil Pertanian yang dikenal dengan Agroindustri.
\end{abstract}

Kata kunci: MEA, arus bebas tenaga kerja, teaching factory, setifikasi kompetensi.

\section{ABSTRACT}

Indonesia entered the ASEAN Economic Community (MEA) as of December 31, 2015. In essence the purpose of the establishment of the MEA is to improve the stability of the economy in the ASEAN region, and is expected to overcome the problems in the economic field among ASEAN countries. The consequences of the MEA deal are the free flow of goods and services, free flow of capital and investment, and free flow of skilled labor for ASEAN countries. Free flow of labor is seen as a threat as well as an opportunity for the state of Indonesia. Therefore the Government of Indonesia through the Education and Culture Ministry, especially the Directorate of Vocational Secondary Education implemented a policy strategy of SMK revitalization. The aim of Vocational Revitalization is to realize the school Link and Match with the Business / Industry World (DuDi) thus eliminating the gap between

*Korespondensi Penulis:

Email : sahir17hirman@gmail.com 
vocational education and DuDi's needs. Three important activities in the implementation strategy of SMK revitalization are the development of industry-based curriculum, teaching factory, and graduate competency certification. Activity is applied to a variety of expertise programs one of which is a program Agribusiness of Agricultural Product Processing (Agroindustry).

Keywords: MEA, free flow of labor, teaching factory, competency certification.

\section{PENDAHULUAN}

Mansyarakat di kawasan ASEAN dapat melakukan transaksi perdagangan baik barang maupun jasa secara bebas sejak diberlakukkannya MEA pada tahun 2015. Kondisi tersebut menuntut kreativitas bangsa Indonesia untuk memiliki daya saing yang kuat. Faktor sumber daya manusia khususnya tenaga kerja terampil merupakan faktor yang sangat penting. Konsekuensi berlakunya MEA adalah arus bebas tenaga kerja yang memungkinkan tenaga kerja dari negaranegara di kawasan ASEAN bisa bebas bekerja di Indonesia dan sebaliknya.

Eksistensi tenanga kerja Indonesia akan lebih diperhitungkan apabila didukung oleh kualitas pendidikan yang memadahi. Pendidikan dan pelatihan mempunyai peranan penting dalam meningkatkan daya saing tenaga kerja. Pendidikan dan pelatihan harus mampu mengantisipasi tantangan dunia kerja yang semakin komplek untuk menghasilkan tenaga kerja yang profesional yang memiliki daya saing yang tinggi. Pendidikan diharapkan dapat melahirkan generasi bangsa ang berkarakter kuat, terampil, kreatif, inovatif, peka terhadap kearifan lokal dan technoprenership (Kemendikbud, 2016). Dalam kaitannya dengan kesiapan untuk memasuki pasar kerja yang lebih luas tersebut, maka tenaga kerja Indonesia harus memiliki kualifikasi dan standar kerja yang bertaraf Internasional.

Negara Indonesia mempunyai bunus demografi yaitu memiliki tenaga kerja pada usia produktif yang besar jumlahnya, hal ini apabila dapat dioptimalkan pendayagunaannya, akan dapat menjadi modal dasar pembangunan untuk mendorong pertumbuhan ekonomi di pasar global. Pada tahun 2010 hingga 2025 diperkirakan akan ada kenaikan permintaan pekerja terampil di kawasan ASEAN yaitu sekitar 14 juta orang, separuh merupakan kebutuhan Indonesia dan pada tahun 2025 di Indonesia akan terjadi kenaikan peluang kerja sebanyak 1,9 juta atau sekitar $1,3 \%$ dari total peluang lapangan kerja (ILO, 2015). Memenuhi permintaan Dunia usaha dan Dunia industri (DuDi) masa mendatang tidaklah mudah apalagi kondisi sekarang masih dihadapkan dengan permasalahan pengangguran. Menurut BPS (2015), terdapat 7,56 juta orang pengangguran terbuka dan $20,76 \%$ berpendidikan SMK.

Pada penyediaan tenaga terampil tingkat menengah terjadi gap antara kebutuhan tenaga kerja di Indonesia dengan penyediaan tenaga kerja sehingga diperlukan program akslerasi sehingga dikeluarkan Instruksi Presiden No 9 tahun 2016 tentang revitalisasi SMK. Dalam inpres ini, Presiden menginstruksikan kepada 12 Menteri Kabinet Kerja untuk mendukung pelaksanaan revitaliasi pendidikan menengah kejuraun salah satunya adalah Kementerian Pendidikan dan Kebudayaan. Direktorat Pendidikan Menengah Kejuruan Kementerian Pendidikan dan Kebudayaan dalam rangka revitalisasi SMK menerapkan kebijakan yang dikenal sebagai strategi implementasi revitalisasi SMK. Tujuan Revitalisasi SMK adalah untuk memujudkan link and Match sekolah dengan Dunia Usaha/Industri (DuDi) untuk mengurangi/ menghilangkan kesenjangan antara pendidikan kejuruan dengan kebutuhan DuDi sehingga meningkatkan kebekerjaan lulusan SMK. Tiga kegiatan penting dalam strategi implementasi revitalisasi SMK adalah pengembangan kurikulum berbasis industri, 
teaching factory, dan sertifikasi kompetensi lulusa. Salah satu revitalisasi pendidikan kejuruan adalah revitalisasi Program Keahlian Agribisnis Pengolahan Hasil Pertanian yang dikenal dengan Agroindustri, yang akan dipaparkan dalam makalah ini.

\section{Bahan dan Metode}

Tulisan makalah ini merupakan komunikasi singkat dari kajian kebijakan revitalisasi SMK khususnya berkaitan dengan pengembangan tenaga terampil level menengah program keahlian agribinsis pengolahan hasil pertanian yang dikembangkan oleh Direktorat Pembinaan Sekolah Menengah Kejuruan. Bahan yang digunakan untuk penulisan artikel ini tediri dari beberapa kebijakan diantaranya adalah Inpres RI Nomor 9 tentang Revitalisasi SMK, Revitalisasi Pendidikan Vokasi, dan Strategi implementasi Revitalisasi SMK. Metode yang digunakan meliputi pengkajian dan telaah dokumen dikaitkan dengan pengalaman epiris penulis untuk menarik suatu kesimpulan.

\section{HASIL DAN PEMBAHASAN}

\section{A. Pengembangan Kurikulum SMK Berbasis Industri}

Perkembangan Kurikulum

Kurikulum pedidikan menengah kejuruan dirancang mengikuti perkembangan yang terjadi di Dunia Usaha dan Dunia Industri (DuDi). Sekarang ini DuDi telah memasuki era perekonomian berbasis pengetahuan yang terbuka dan bertumpu pada persaingan bebas bahkan memasuki era industri digital 4.0. Era perekonomian berbasis pengetahuan ditandai dengan persaingan dalam menguasai teknologi pada era digital. Terjadinya perubahan pesat teknologi informasi dan komunikasi (TIK) dan penguasaan media TIK yang merata di tengah semakin cepat dan meluasnya cakupan penyebaran dan pertukaran informasi. Pada era digital jenis pekerjaan seseorang berubah dengan cepat sesuai dengan kebutuhan pasar kerja. Pekerjaan yang semula dilakukan secara manual dengan mengandalkan tenaga manusia telah digantikan oleh mesin dan teknologi informasi. Beberapa jenis pekerjaan yang ada saat ini, perlahan akan hilang pada 10 tahun ke depan. Diperkirakan 35\% keterampilan dasar pada dunia kerja akan berubah pada tahun 2020, dan hampir 2 miliar pekerja berisiko kehilangan pekerjaan (Kemendikbud, 2016). Karena itu, pendidikan dan pelatihan seharusnya melakukan pengembangan kurikulum dengan banyak pilihan keterampilan yang sesuai dengan minat peserta didik dan perkembangan kebutuhan pasar kerja.

Kurikulum pendidikan dan pelatihan vokasi dalam hal ini pendidikan menengah kerjuruan perlu membekali lulusannya dengan berbagai kecakapan yang lebih umum, yaitu kecakapan hidup dan berkarier, kecakapan dalam belajar dan berinovasi, serta kecakapan memanfaatkan informasi, media, dan teknologi. Kecakapan hidup dan berkarier (life and career skills) menurut Kemendikbud (2017) memiliki komponen, yakni (1) fleksibilitas dan adaptabilitas, (2) memiliki inisiatif dan dapat mengatur diri sendiri, (3) interaksi sosial dan antar-budaya, (4) produktivitas dan akuntabilitas mengelola proyek dan menghasilkan produk, dan (5) kepemimpinan dan tanggung jawab. Selanjutnya dijelaskan pula bahwa, kecakapan dalam belajar dan berinovasi (learning and innovation skills) memiliki komponen (1) berpikir kritis dan mengatasi masalah, (2) kecakapan berkomunikasi dan berkolaborasi, dan (3) kreativitas dan inovasi. Sementara itu, kecakapan media informasi dan teknologi (information media and technology skills) memiliki komponen (1) literasi informasi, (2) literasi media, dan (3) literasi TIK. Pembekalan kecakapan semacam ini dikemas dengan istilah 
Keterampilan Abad XXI (21st Century Skills).

Di samping literasi dan kompetensi, pembelajaran mengacu abad XX1 juga menekankan pada pendidikan karakter. Pendidikan karakter sejalan dengan fungsi pendidikan nasional Indonesia yang tertuang dalam Undang-Undang No. 20/2003 tentang Sistem Pendidikan Nasional, Bab II pasal 3 yang menyatakan bahwa, "Pendidikan nasional berfungsi mengembangkan kemampuan dan membentuk watak serta peradaban bangsa yang bermartabat dalam rangka mencerdaskan kehidupan bangsa, bertujuan untuk berkembangnya potensi peserta didik agar menjadi manusia yang beriman dan bertakwa kepada Tuhan Yang Maha Esa, berakhlak mulia, sehat, berilmu, cakap, kreatif, mandiri, dan menjadi warga negara yang demokratis serta bertanggung jawab". Tujuan pendidikan ini menekankan pada "karakter kuat" yang sampai saat ini tetap dipertahankan. Secara ringkas hubungan antara tujuan pendidikan, kurikulum dan kebutuhan DuDi ditampilkan pada Gambar 1.

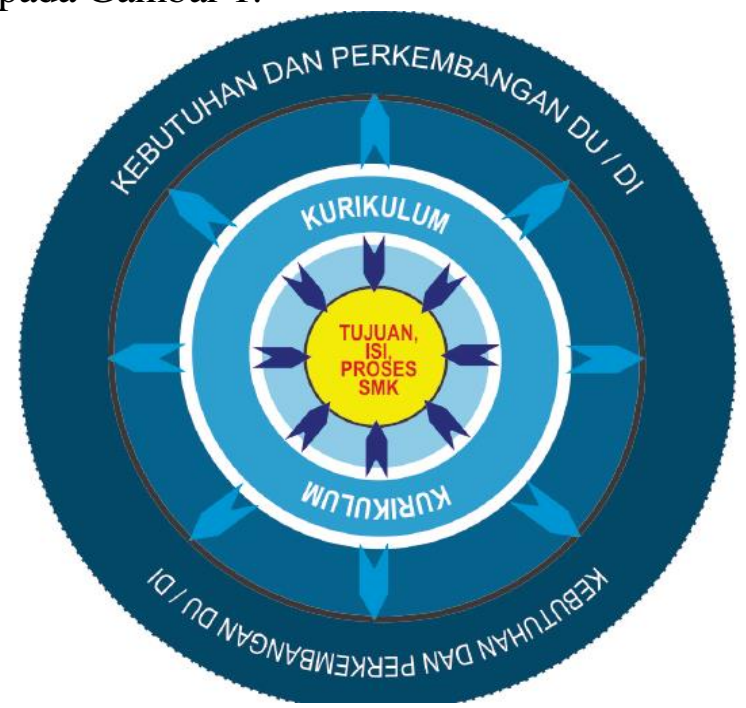

Sumber: Direktorat Pembinaan SMK, 2017

Gambar 1. Hubungan antara tujuan SMK, kurikulum dan kebutuhan DuDi

Prinsip Pengembangan Kurikulum SMK.

Prinsip umum dalam pengembangan kurikulum SMK terdiri atas lima prinsip yaitu relevansi, fleksibilitas, kontinuitas, praktis dan efektifitas (Direktorat Pembinaan SMK, 2017). Relevansi terdiri atas relevansi ke dalam dan relevansi ke luar. Relevansi ke dalam adalah konsistensi antara komponenkomponen kurikulum, yaitu tujuan SMK, isi, proses penyampaian dan penilaian yang ada di SMK. Relevansi ke luar adalah relevan dengan tuntutan, kebutuhan, dan perkembangan DuDi. Fleksibilitas kurikulum bersifat luwes yaitu kurikulum tersebut mudah untuk disesuaikan, diubah, dilengkapi atau berdasarkan tuntutan dan keadaan ekosistem dan kemampuan setempat, jadi tidak statis atau kaku. Kontinuitas mempunyai arti bahwa penyusunan kurikulum berkesinambungan dengan proses dan perkembangan belajar anak. Kurikulum pendidikan berkesinambungan antara satu tingkat kelas dengan kelas lainnya, antara satu jenjang pendidikan dengan pekerjaan Praktis mempunyai arti bahwa keterampilan dituliskan dalam kurikulum diajarkan sesuai dengan implementasi di DuDi dan menggunakan alat-alat yang disesuaikan dengan kebutuhan DuDi. Efektivitas mempunyai arti abwa keberhasilan pelaksanaan suatu kurikulum seharusnya dapat ditinjau dari kualitas dan kuantitasnya.

\section{Strategi Pembelajaran Kurikulum SMK}

Pembelajaran kurikulum SMK mengikuti tiga strategi yaitu Link and match, deman driven dan dua based progam (Direktorat Pembinaan SMK, 2017). Link and match merupakan salah satu kebijakan pendidikan yang sering diterjemahkan keterkaitan dan kesepadanan dengan DuDi. Kebijakan "Link and match" mengimplikasikan wawasan sumber daya manusia, wawasan masa depan, wawasan mutu dan wawasan keunggulan, wawasan profesionalisme, wawasan nilai tambah dan wawasan ekonomi dalam penyelenggaraan pendidikan khususnya pendidikan kejuruan. 
Pendekatan "demand-driven" mengharapkan justru pihak dunia usaha, dunia industri atau dunia kerja yang harusnya lebih berperan dalam menentukan mendorong dan menggerakan pendidikan kejuruan sebagai yang berkepentingan dari sudut tenaga kerja. Pendidikan berbasis program sistem ganda ( dual-based program) mengharapkan supaya program pendidikan kejuruan dilaksanakan di dua tempat. Teori dan praktek dasar kejuruan dilaksanakan di sekolah, sedangkan keterampilan produktif dilaksanakan di Dunia Usaha/Industri dengan prinsip belajar sambil bekerja (Learning by doing).

Program Penyelarasan Kurikulum SMK dengan Dunia Usaha/Industri

Agar terjadi kesesuian antara kompetensi yang diajarkan di sekolah dengan kompetensi yang diperlukan DuDi maka dilakukan penyelarasan kurikulum SMK yang akan memantapkan model kesesuaian dan keterkaitan (link and match) dengan Dunia Usaha/Industri. Pelaksanaan kurikulum dalam proses pembelajaran dilakukan untuk membentuk tahapan pembelajaran mengacu pada fase pembelajaran di sekolah ataupun praktik di industri dan berorientasi pada hasil proses pembelajaran yang diinginkan. Berdasarkan Peraturan Dirjen 07/D.D5/KK/2018 tentang Struktur Kurikulum Sekolah Menengah Kejuruan (SMK)/ Madrasah Aliyah Kejuruan (MAK), struktur kurikulum pada seluruh program keahlian Agribisnis Pengolahan Hasil Pertanian terdiri dari Muatan Nasional, Muatan Kewilayahan dan Dasar-Dasar Program Keahlian. Struktur Kurikulum Kompetensi Keahlian Agribisnis Pengolahan Hasil Pertanian dapat dilihat pada Tabel 1.

Tabel 1. Struktur Kurikulum Kompetensi Keahlian Agribisnis Pengolahan Hasil Pertanian

\begin{tabular}{|c|c|c|c|c|c|c|c|}
\hline \multirow[t]{3}{*}{ Mata Pelajaran } & \multicolumn{6}{|c|}{$\begin{array}{l}\text { Jumlah Jam Tiap Kelas } \\
\text { per Minggu (Jam) }\end{array}$} & \multirow{3}{*}{$\begin{array}{l}\text { Alokasi } \\
\text { Waktu } \\
(\mathrm{Jam})\end{array}$} \\
\hline & \multicolumn{2}{|c|}{ VII } & \multicolumn{2}{|c|}{ VIII } & \multicolumn{2}{|l|}{ IX } & \\
\hline & 1 & 2 & 1 & 2 & 1 & 2 & \\
\hline \multicolumn{8}{|l|}{ A. Muatan Nasional } \\
\hline \begin{tabular}{l|l} 
& Pendidikan Agama dan Budi Pekerti
\end{tabular} & 3 & 3 & 3 & 3 & 3 & 3 & 318 \\
\hline $\begin{array}{l}\text { Pendidikan Pancasila dan } \\
\text { Kewarganegaraan }\end{array}$ & 2 & 2 & 2 & 2 & 2 & 2 & 212 \\
\hline Bahasa Indonesia & 4 & 4 & 3 & 3 & 2 & 2 & 320 \\
\hline Matematika & 4 & 4 & 4 & 4 & 4 & 4 & 424 \\
\hline Sejarah Indonesia & 3 & 3 & & & & & 108 \\
\hline \begin{tabular}{|l|l} 
Bahasa Inggris dan Bahasa Asing \\
Lainnya*)
\end{tabular} & 3 & 3 & 3 & 3 & 4 & 4 & 352 \\
\hline Jumlah A & 19 & 19 & 15 & 15 & 15 & 15 & 1.734 \\
\hline \multicolumn{8}{|l|}{ B. Muatan Kewilayahan } \\
\hline \begin{tabular}{l|l} 
Seni Budaya \\
\end{tabular} & 3 & 3 & & & & & 108 \\
\hline \begin{tabular}{l|l} 
Pendidikan Jasmani, Olahraga dan \\
Kesehatan
\end{tabular} & 2 & 2 & 2 & 2 & & & 144 \\
\hline Jumlah B & 5 & 5 & 2 & 2 & & & 252 \\
\hline \multicolumn{8}{|l|}{ C. Muatan Peminatan Kejuruan } \\
\hline \multicolumn{8}{|l|}{ C1. Dasar Bidang Keahlian } \\
\hline \begin{tabular}{l|l} 
& Simulasi dan Komunikasi Digital \\
\end{tabular} & 3 & 3 & & & & & 108 \\
\hline Fisika & 2 & 2 & & & & & 72 \\
\hline
\end{tabular}




\begin{tabular}{|l|l|l|l|l|l|l|l|r|}
\hline & Biologi & 3 & 3 & & & & & 108 \\
\hline & Kimia & 2 & 2 & & & & & 72 \\
\hline C2. Dasar Program Keahlian & & & & & & & 144 \\
\hline & $\begin{array}{l}\text { Dasar Penanganan Bahan Hasil } \\
\text { Pertanian }\end{array}$ & 4 & 4 & & & & & 144 \\
& $\begin{array}{l}\text { Dasar Proses Pengolahan Hasil } \\
\text { Pertanian }\end{array}$ & 4 & 4 & & & & & 144 \\
\hline $\begin{array}{l}\text { Dasar Pengendalian Mutu Hasil } \\
\text { pertanian }\end{array}$ & 4 & 4 & & & & & 280 \\
\hline C3. Kompetensi Keahlian & & & & & & & & 664 \\
\hline & Produksi Hasil Nabati & - & - & 9 & 9 & 10 & 10 & 350 \\
\hline & Produksi Hasil Hewani & - & - & 5 & 5 & 5 & 5 & 420 \\
\hline $\begin{array}{l}\text { Produksi Komoditas Perkebunan dan } \\
\text { Herbal }\end{array}$ & - & - & 6 & 6 & 6 & 6 & 524 \\
\hline $\begin{array}{l}\text { Keamanan Pangan dan Sistem } \\
\text { Jaminan Mutu (Quality Sistem) }\end{array}$ & - & - & 4 & 4 & 4 & 4 & 3030 \\
\hline & Produk Kreatif dan Kewirausahaan & - & - & 7 & 7 & 8 & 8 & 5016 \\
\hline
\end{tabular}

Kompetensi keahlian yang dikembangkan Direktorat Pembinaan SMK guna mendukung penyiapan tenaga terampil level menengah pada bidang Agroindustri diantaranya adalah Agribisnis Pengolahan Hasil Pertanian, Pengawasan Mutu Hasil Pertanian, Agroindustri dan Teknologi Hasil Perikanan. Kurikulum yang dikembangkan secara nasional harus diselaraskan dengan kebutuhan DuDi. Program penyelarasan kurikulum bersama industri diharapkan mampu menambah / menyesuaikan kompetensi lulusan SMK, sehingga sesuai dengan pasar kerja. Secara lebih teknis penyesuaan kurikulum meliputi penyesuaian jenis kompetensi, penyesuaian materi pembelajaran dan penyesuaian kometensi penilaian dan adopsi budaya dan tata nilai industri dalam pembelajaran. Selain itu, adanya penyelarasan kurikulum SMK diharapkan dapat meningkatkan lulusan SMK yang siap kerja sesuai dengan kebutuhan Dunia Usaha/Industri. Karena jenis DuDi bervariasi maka sekolah menentukan jenis Du/Di yang sesuai dengan potensi.
Penyelarasan kurikulum di sekolah dengan dunia kerja diharapkan dapat menghasilkan kualitas lulusan atau pencari kerja yang dapat memenuhi kualifikasi dan persyaratan yang dibutuhkan dunia kerja atau dapat melakukan wirausaha secara mandiri. Tujuan akhir dari penyelarasan ini adalah tercipta paradigma "The right man on the right place", memperkaya lapangan pekerjaan melalui wirausaha dan sekaligus memperkecil angka penggangguran. Pelakanaan penyelarasan kurikulum mengikuti pola seperti ditunjukkan pada Gambar 2.

Agar kurikulum yang diterapkan di sekolah sesuai dengan industri, maka perlu adanya alur untuk menyelarasakan kurikulum tersebut. Alur ini akan mempermudah sekolah menjalankan dan mengimplementasikan kurikulum industri.

Menurut Direktorat Pembinaan SMK (2017) alur penyelarasan kurikulum SMK dimulai dari SMK mengidentifikasi kemampuan peserta didik dan sarana prasarana, sedangkan DuDi mengidentifikasi kebutuhan kompetensi Industri yang sesuai 
dengan SMK, apabila hal ini sudah dilaksanakan maka antara SMK dan Du/Di dapat menyelaraskan kurikulum yang berlaku di SMK sesuai dengan kompetensi yang ada pada industri. Setelah kurikulum industri terbentuk, SMK mulai dapat menerapkan kurikulum industri pada proses pembelajaran di sekolah. Selanjutnya, DuDi dapat memonitoring tentang proses kurikulum yang berjalan. Akhirnya akan dihasilkan lulusan SMK yang siap kerja sesuai dengan kebutuhan industri.

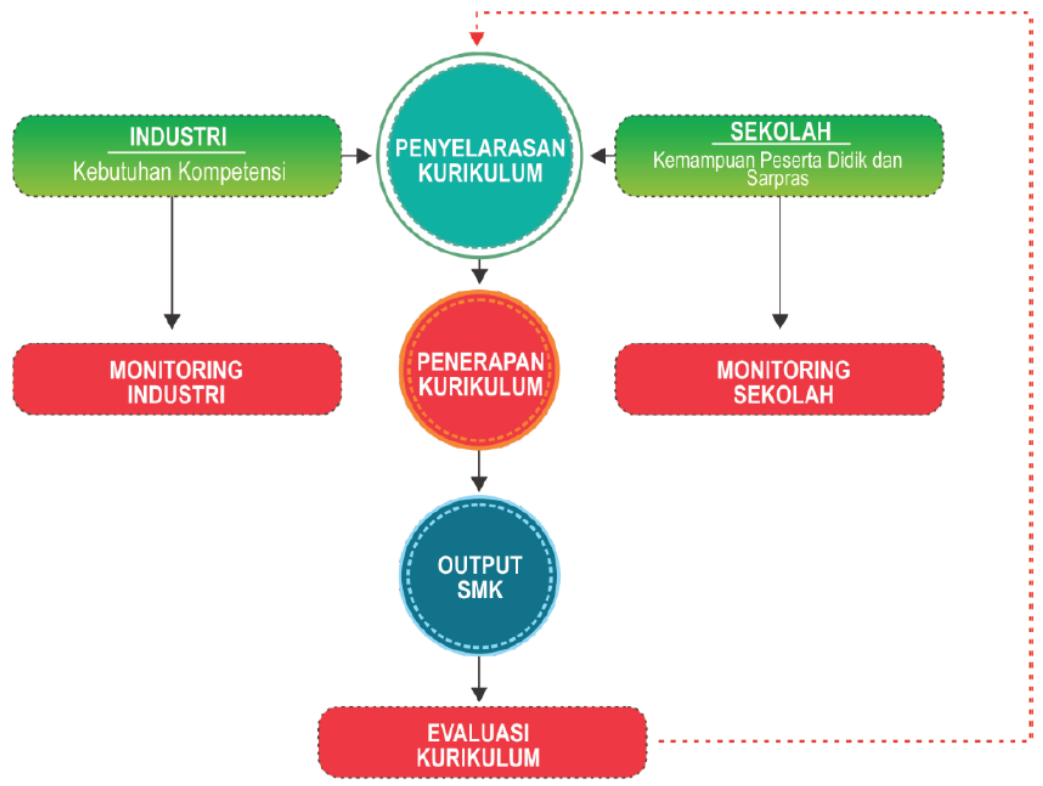

Sumber: Direktorat Pembinaan SMK, 2017

Gambar 2. Program penyelerasan kurikulum SMK

Pembelajaan Sistem Blok

Pembelajaran sistem blok merupakan cara pembelajaran dengan menyatukan jumlah jam dalam mingguan (blok mingu), bulanan (blok bulan) atau semester (blok semester) sehingga diperoleh blok jam yang besar. Pembelajaran sistem blok merupakan bagian dari implementasi penyelarasan kurikulum pembelajaran SMK dengan Dunia Usaha/Industri. Pembelajaran sistem blok mengelompokan jam belajar efektif dalam satuan waktu yang terangkum dan memungkinkan peserta didik mengikuti serta menerima materi pembelajaran secara maksimal dan utuh. Pembelajaran sistem blok ini merupakan aplikasi dari teori kejuruan Prosser yang menyatakan bahwa pendidikan kejuruan akan efektif jika pengalaman latihan untuk membentuk kebiasaan kerja dan kebiasaan berpikir yang benar diulang-ulang sehingga sesuai seperti yang diperlukan dalam pekerjaan nantinya. Pembelajaran yang dilakukan secara terusmenerus dan berulang-ulang akan lebih cepat diserap oleh peserta didik daripada pembelajaran yang terputus-putus. Dapat diambil contoh ketika peserta didik menerima pelajaran membuat tahu, maka peserta didik ini akan lebih mudah menyerap materi membuat tahu yang dilaksanakan dengan pembelajaran selama satu minggu penuh daripada pembelajaran yang terputus di lain hari.

Pembelajaran sistem blok juga mampu mengatasi keadaan yang tidak efisien ketika pelajaran praktik. Contohnya, saat peserta didik sedang asik mengerjakan pekerjaan dan belum selesai, tetapi karena waktunya sudah habis menyebabkan produk tidak jadi. Di sisi lain pembelajaran sistem blok juga tepat digunakan pada pembelajaran berbasis teaching factory (praktik dilaksanakan pada 
unit produksi di miliki sekolah seperti pabrik roti, pabrik tahu, sirup buah dan lai-lain), karena dengan adanya sistem blok ini dapat mempermudah penyelesaian produk yang diproduksi di teaching factory.

\section{B. Teaching Factory}

Konsep pembelajaran berbasis teaching factory menekankan pendidikan yang lebih demand oriented, membekali para peserta didik dengan karakter kewirausahaan (technopreneurship) dan melibatkan DuDi sebagai mitra utama (Ditrektorat Pembinaan SMK, 2017). Melalui pola teaching factory, optimalisasi kerjasama pendidikan dengan industri berdampak pada proses pembelajaran yang semakin berorientasi pada kebutuhan industri. Kerjasama (partnership) yang dibangun secara sistematis dan berdasarkan pada win-win solution menjadikan teaching factory sebagai penghubung antara dunia pendidikan dengan DuDi yang akan mendorong terjadinya transfer teknologi guna meningkatkan kualitas guru dan softskill bagi peserta didik. Elemen teaching factory meliputi jadwal blok, RPP, Jobsheet, Produk, dan lulusan SMK (GIZ, 2015).

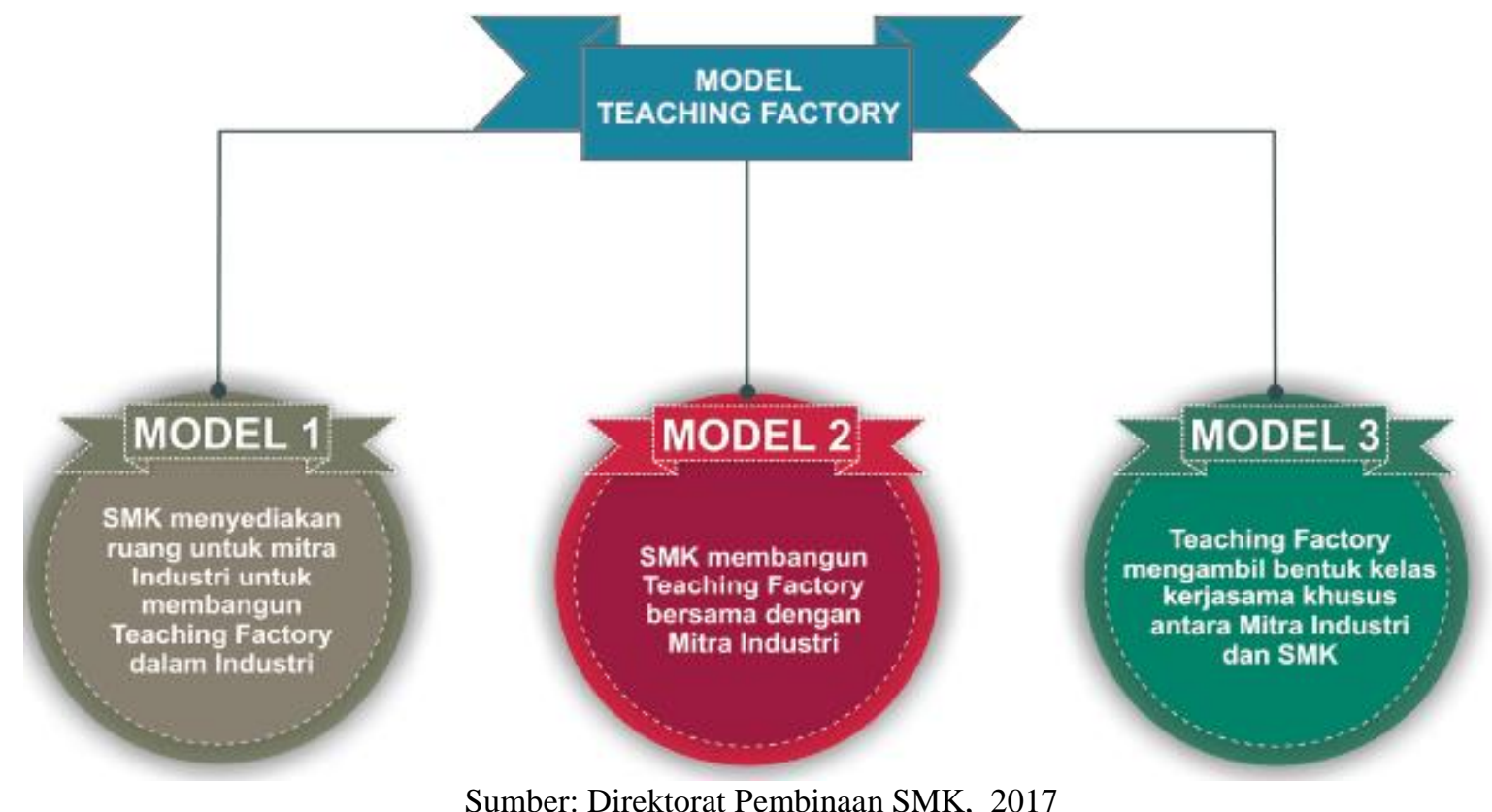

Gambar 3. Model Teaching Factory

Beberapa alasan penting mengapa teaching factory perlu diselenggarakan di sekolah antara lain: a) Meningkatkan kompetensi guru dan peserta didik, b) Mendorong terciptanya budaya mutu di sekolah, c) Menciptakan budaya industri di sekolah, d) Wahana kreativitas dan inovasi peserta didik dan guru, sarana pengembangan entrepreneurship di sekolah, dan e) Tempat magang dan penampungan lulusan yang belum mendapat pekerjaan di dunia industri atau dunia usaha. Model pembelajaran teaching factory di format untuk meningkatkan kompetensi peserta didik dalam mata pelajaran produktif. Model teaching factory menerapkan enam langkah seperti model pembelajaran dengan menggunakan metode R\&D. Enam langkah dari satu siklus model ini, adalah 1 . Menerima pemberi order 2. Menganalisis order, 3. Menyatakan kesiapan mengerjakan order, 4. Mengerjakan order, 5. Melakukan quality control, dan 6. Menyerahkan order.

Pembelajaran melalui teaching factory ini bertujuan untuk menumbuhkembangkan karakter dan etos kerja (disiplin, tanggung 
jawab, jujur, kerjasama, kepemimpinan) yang dibutuhkan DuDi, meningkatkan kualitas hasil pembelajaran dari sekedar membekali kompetensi (competency based training) menuju ke pembelajaran yang membekali kemampuan memproduksi barang/jasa (production based training), sebagai wahana kreativitas pengembangan technopreneur, membangun budaya industri di sekolah, sebagai sumber keuntungan bagi sekolah melalui Unit Produksi Jurusan (UPJ) yang sekaligus sebagai unit praktik bagi peserta didik.

Pembelajaran berbasis teaching factory harus didasarkan pada beberapa elemen penting yang mendukung berlangsungnya proses pembelajaran tersebut meliputi jadwal blok, RPP, Jobsheet, Produk, dan Lulusan SMK. Adanya RPP dan jobsheet ini sebagai dasar untuk membuat produk sesuai permintaan dari mitra industri. Proses pembelajaran dalam teaching factory berada pada proses pembuatan produk ini. Keberhasilan pembuatan suatu produk yang sesuai dengan permintaan industri menjadi kunci dihasilkannya lulusan SMK yang kompeten.

\section{Uji Sertifikasi Profesi}

Mutu lulusan pendidikan vokasi secara ideal ditentukan berdasarkan penguasaan atas Standar Kompetensi Kerja Nasional Indonesia. Berdasarkan standar kompetensi tersebut, dirumuskan suatu sistem pengujian dan sertifikasi. Beberapa upaya telah dilakukan untuk meminimalisasi kesenjangan kompetensi kerja lulusan pendidikan vokasi dengan kebutuhan dunia usaha/ dunia industri, antara lain melalui penyusunan skema sertifikasi bagi lulusan pendidikan vokasi dengan melibatkan asosiasi profesi dan DUDI maupun dalam pelaksanaan uji kompetensi. Lulusan yang memperoleh sertifikat adalah lulusan yang memenuhi persyaratan kecakapan kerja yang telah lulus uji kompetensi. Persyaratan tersebut dimulai dari (1) pembelajaran yang benar berbasis SKKNI atau standar relevan lain, yaitu menjadikan peserta didik sebagai subjek pembelajar yang miliki karakter, kompetensi, mandiri, bertanggung jawab, kreatif, inovatif, dan kemampuan kewirausahaan; (2) tersedianya tempat uji kompetensi yang menyediakan peralatan uji sesuai dengan standar kompetensi di sekolahnya; dan (3) asesor terlisensi BNSP yang memiliki sertifikat yang sesuai dengan materi uji kompetensi. Sertifikasi Kecakapan Kerja tersebut diberikan oleh Lembaga sertifikasi Profesi (LSP) yang terlisensi BNSP.

Dalam rangka membekali lulusan SMK dengan sertifikat kompetensi yang diakui dunia usaha/dunia industri sehingga lulusan SMK tersebut memiliki daya saing yang tinggi, maka sejak tahun 2015 Direktorat Pembinaan SMK, Kemendikbud dengan Badan Nasional Sertifikasi Profesi (BNSP) telah melaksanakan kegiatan pengembangan SMK menjadi Lembaga Sertifikasi Pihak Pertama (LSP-P1). Adapun lingkup kegiatan pengembangan SMK menjadi LSP-P1 terdiri dari (i) fasilitasi persiapan dan pelatihan asesor kompetensi; (ii) penyiapan Tempat Uji Kompetensi (TUK); (iii) penyiapan materi uji kompetensi sesuai skema sertifikasi; serta (iv) pelatihan penyusunan dan penerapan dokumen mutu LSP. Setiap calon lulusan SMK akan mengikuti uji kompetensi/sertifikasi kompetensi yang dilaksanakan di LSP-P1 di sekolah masingmasing atau pada LSP-P1 SMK terdekat. Calon lulusan SMK juga dapat juga mengikuti uji kompetensi yang diselenggarakan LSP-P3 yang didirikan oleh industri atau asosiasi profesi yang bermitra dengan SMK. Jika lulus uji kompetensi, peserta akan mendapatkan sertifikat sebagai bukti pengakuan atas kompetensi yang dimilikinya. Sertifikasi Kerangka Kualifikasi Nasional Indonesia (KKNI) yang dikembangkan untuk SMK 3 tahun adalah KKNI level 2 sedangkan untuk 4 tahun KKNI 
level 3. KKNI terdiri atas 9 (sembilan) level kualifikasi yang dapat menyandingkan, menyeratakan, dan mengintegrasikan antara bidang pendidikan dan bidang pelatihan kerja serta pengalaman kerja dalam rangka pemberian pengakuan kompetensi kerja sesuai dengan struktur pekerjaan di berbagai sektor. KKNI menjadi acuan dalam penyusunan capaian pembelajaran lulusan dari setiap jenjang kualifikasi. Gambaran keterkaitan antara KKNI dengan bidang pendidikan dan pelatihan dapat dilihat pada Gambar 4.

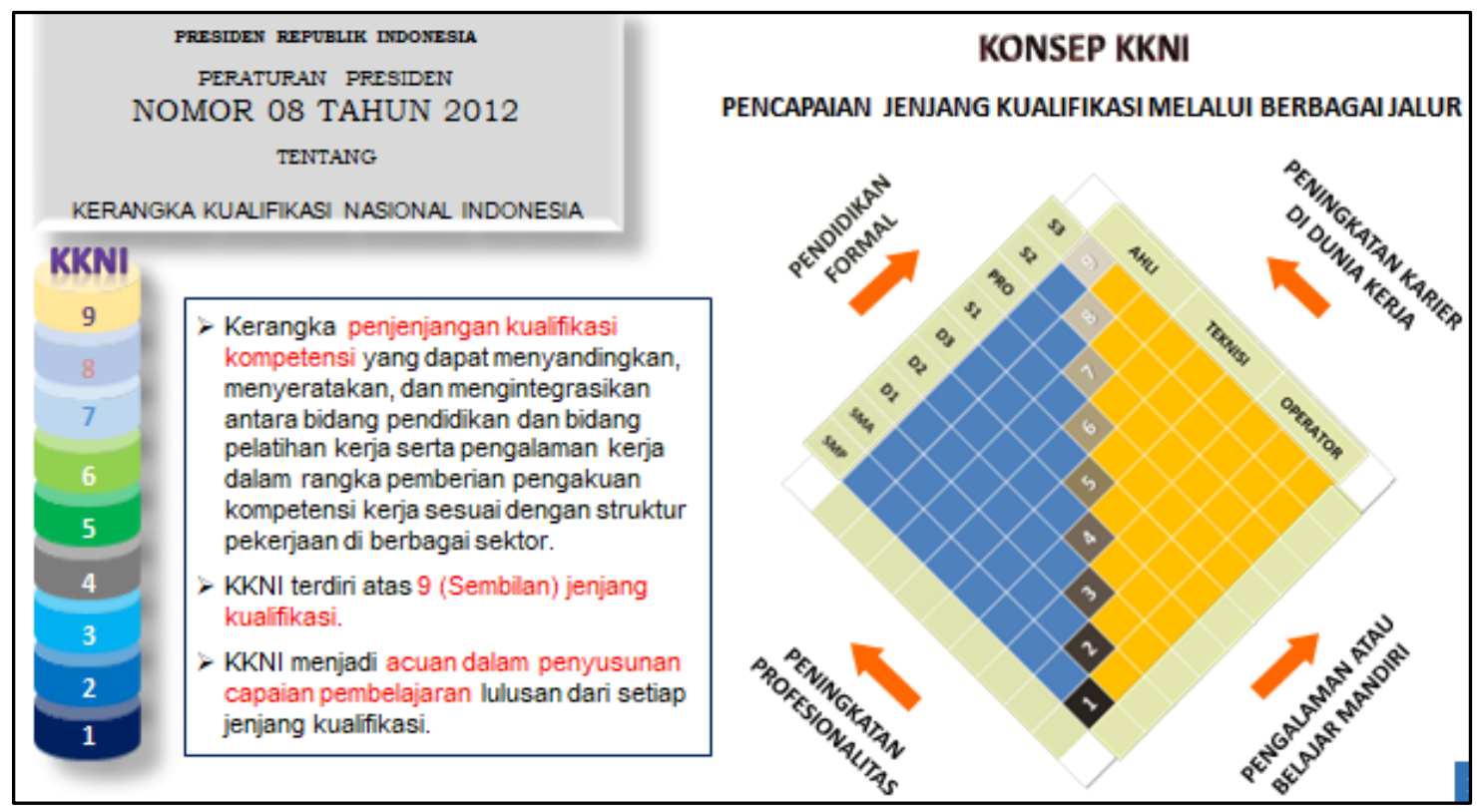

Sumber : BSNP 2018

Gambar 4. Keterkaitan antara KKNI dengan bidang pendidikan dan pelatihan

\section{Skema Sertifikasi Profesi}

Skema sertifikasi profesi merupakan persyaratan sertifikasi spesifik yang dipakai sebagai dasar pelaksanaan uji kompetensi yang disusun oleh LSP dan ditetapkan oleh BNSP. Menurut jenisnya skema sertifikasi profesi terdiri atas 5 jenis yaitu skema sertifikasi KKNI, kluster, unit kompetensi, okupasi, dan skema sertifikasi profisiensi.

Skema sertifikasi profesi KKNI adalah skema sertifikasi yang disusun berdasar pada penjenjangan kualifikasi KKNI sesuai Perpres No. 8 Tahun 2012 dari level satu sampai sembilan. Penyusunan skema ini mengacu pada KKNI atau kualifikasi yang setara berdasarkan diskriptor KKNI. Skema sertifikasi profesi Okupasi Nasional mengacu pada jabatan kerja di industri yang diberlakukan secara nasional. Skema sertifikasi profesi klaster mengacu pada permintaan khusus dari pengguna lulusan / industri yang selaras dengan materi pembelajaran. Skema sertifikasi KKNI dapat dipecah menjadi beberapa bagian skema sertifikasi klaster. Skema sertifikasi klaster yang digunakan di SMK bersumber pada SKKNI sesuai dengan kurikulum pendidikan di SMK yang telah ditetapkan oleh BNSP bersama Ditjen Dikdasmen Kemendikbud atau dengan kementerian terkait. Skema sertifikasi profesi unit kompetensi adalah skema sertifikasi yang dikembangkan berdasarkan satuan unit kompetensi yang diambil dari SKKNI atau standar lain yang ditetapkan BNSP. Pelaksanaan sertifikasi profesi dapat dilangsungkan utuk beberapa unit kompetensi secara bersamaan. Sertifikasi profesi profisiensi adalah skema sertifikasi berdasarkan kriteria-kriteria (norm) kunci yang ada pada standar sehingga tidak semua 
kriteria unjuk kerja diujikan. Skema ini digunakan untuk memelihara kompetensi seseorang yang telah kompeten dan mempunyai pengalaman dibidangnya.

Tujuan penyusunan skema sertifikasi adalah (a) untuk memastikan sertifikasi dilakukan menggunakan standar dan prosedur yang sama; (b) Sebagai acuan Uji Kompetensi bagi peserta uji kompetensi, Tempat Uji Kompetensi dan Asesor dan (c) untuk memastikan kompetensi klaster sesuai dengan Skema sertifikasi KKNI. Contoh skema sertifikasi bidang agroindustri yaitu Skema Sertifikasi KKNI Level IV pada Kompetensi Keahlian Agribisnis Pengolahan Hasil Perikanan mengacu pada SKKNI
Nomor 250 Tahun 2009 Tentang Sektor Industri Pengolahan Sub Sektor Industri Makanan dan Minuman Bidang Industri Pengolahan dan Pengawetan Ikan Sub Bidang Industri Pengolahan Udang, dan SKKNI Nomor 78 (Pembekuan Tuna), 107 (pengolahan rumput laut), 158 (pengalengan tuna) dan 284 (deversifikasi surimi) Tahun 2016 yang dikembangkan oleh LSP PPPPTK Pertanian Canjur.

Jenis Kemasan : KKNI

Nama Skema : Skema Sertifikasi KKNI Level IV pada Kompetensi Keahlian Agribisnis Pengolahan Hasil Perikanan

\begin{tabular}{|c|c|c|}
\hline NO & KODE UNIT & JUDUL UNIT KOMPETENSI \\
\hline A. & \multicolumn{2}{|l|}{ Kompetensi Inti } \\
\hline 1 & C.10SRM00.007.1 & $\begin{array}{l}\text { Melaksanakan Keselamatan dan Kesehatan Kerja } \\
\text { (K3) di Tempat Kerja }\end{array}$ \\
\hline 2 & C.10SRM00.034.1 & $\begin{array}{l}\text { Mengawasi Penerapan Good Manufacturing } \\
\text { Practices (GMP) dan Sanitation Standard } \\
\text { Operating Procedure (SSOP) }\end{array}$ \\
\hline 3 & PHU.KS03.009.01 & $\begin{array}{l}\text { Menganalisis Bahaya dan Pengendalian Titik } \\
\text { Kritis Sesuai Prosedur HACCP }\end{array}$ \\
\hline B. & \multicolumn{2}{|l|}{ Kompetensi Pilihan } \\
\hline 1 & C.102900.017.01 & Membuat Dodol Rumput Laut \\
\hline 2 & C.102900.022.01 & Membuat Selai Rumput Laut \\
\hline 3 & C.102900.020.01 & Membuat Permen Jelly \\
\hline 4 & C.10SRM00.008.1 & Membuat Surimi \\
\hline 5 & C.10SRM00.009.1 & Membuat Bakso Ikan \\
\hline 6 & C.10SRM00.021.1 & Membuat Sosis Ikan \\
\hline 7 & C.10SRM00.024.1 & Membuat Naget Ikan \\
\hline 8 & PHU.PL02.001.01. & Menyiapkan Peralatan Pengolahan Udang. \\
\hline 9 & PHU.UB02.002.01. & $\begin{array}{l}\text { Menyortir mutu (grading) Jenis dan Ukuran } \\
\text { Udang Untuk Produk Udang Beku }\end{array}$ \\
\hline 10 & PHU.UB02.003.01. & Menyiangi / membuang Kepala Udang. \\
\hline 11 & PHU.UB02.004.01. & Menyiangi /Mengupas Kulit Udang. \\
\hline 12 & PHU.UB02.005.01. & $\begin{array}{l}\text { Mencuci daging udang tanpa kulit dan kepala } \\
\text { dengan air dingin. }\end{array}$ \\
\hline 13 & PHU.UB02.006.01. & $\begin{array}{l}\text { Menimbang dan Menyusun Udang Untuk } \\
\text { Dibekukan. }\end{array}$ \\
\hline 14 & PHU.UB02.007.01. & Membekukan Udang ( Cooling / Freezing ). \\
\hline 15 & PHU.UB02.008.01. & Menggelas (Glazing) Produk Udang Beku. \\
\hline 16 & PHU.PP02.012,01 & Mengemas dan mengepak Hasil Produk \\
\hline
\end{tabular}




\begin{tabular}{|c|l|l|}
\hline & & Pengolahan Udang. \\
\hline 17 & PHU.PP02.013.01 & $\begin{array}{l}\text { Memberi Tanda Label dan Memberi Kode Hasil } \\
\text { Produk Pengolahan Udang }\end{array}$ \\
\hline 18 & PHU.PP02.014.01 & $\begin{array}{l}\text { Menyimpan hasil produk pengolahan udang } \\
\text { dalam gudang dingin (cold storage) }\end{array}$ \\
\hline 19 & C.102130.002.02 & $\begin{array}{l}\text { Menyiapkan Bahan Produksi Pembekuan Ikan } \\
\text { Tuna }\end{array}$ \\
\hline 20 & C.102130.007.02 & Melakukan Butchering \\
\hline 21 & C.102130.008.02 & Melakukan Loining \\
\hline 22 & C.102130.009.02 & Melakukan Trimming \\
\hline 23 & C.102130.010.02 & Melakukan Skinning \\
\hline 24 & C.102130.011.02 & Melakukan Grading \\
\hline 25 & C.102130.012.02 & Melakukan Cutting \\
\hline 26 & C.102130.013.02 & Melakukan pembungkusan (wrapping) \\
\hline 27 & C.102130.014.02 & Menimbang Produk Tuna \\
\hline 28 & C.102130.016.02 & $\begin{array}{l}\text { Melakukan Penyimpanan Produk Dalam } \\
\text { Chilling Room }\end{array}$ \\
\hline 29 & C.102130.022.02 & Melakukan Pembekuan \\
\hline 30 & C.102130.024.02 & Melakukan Pengemasan \\
\hline 31 & C.102130.026.02 & Mengelola Dokumen Ekspor \\
\hline
\end{tabular}

\section{Sertifikasi}

Pengukuran dan penilaian keberhasilan peserta didik dalam mencapai kemampuan sesuai standar kompetensi harus diuji oleh asesor dari sekolah sendiri atau asesor sekolah lain. Penetapan kelulusan peserta didik nantinya dinyatakan dengan pemberian sertifikat yang memuat aspek-aspek kompetensi sesuai dengan yang diujikan. Evaluasi dilaksanakan secara terpadu meliputi persiapan, pelaksanaan, dan hasil (produk).

Uji sertifikasi profesi dapat dilakukan lebih dari satu penguji pada satu bidang, sebagai contoh peserta didik mempunyai kemampun di bidang pengolahan udang, di sekolah peserta didik dapat melakukan ujian sertifikasi profesi untuk mendapatkan sertifikat P1, dengan penguji (asesor ) dari SMK lain, peserta didik dapat memperoleh sertifikat P2 dengan melakukan uji sertifikasi profesi dari pihak luar sekolah (PPPPTK / BLK), sedangkan untuk mendapatkan sertifikat P3 peserta didik dapat melakukan uji sertifikasi profesi di Industri yang sudah menjadi mitra kerja SMK.

Sertifikasi kompetensi kerja merupakan suatu pengakuan terhadap tenaga kerja yang mempunyai pengetahuan, ketrampilan dan sikap kerja sesuai dengan standar kompetensi kerja yang telah dipersyaratkan, dengan demikian sertifikasi kompetensi memastikan bahwa tenaga kerja (pemegang sertifikat) tersebut terjamin akan kredibilitasnya dalam melakukan suatu pekerjaan yang menjadi tugas dan tanggung jawabnya.

\section{Kesimpulan}

Konsekuensi diberlakukannyan MEA, Direktorat Pendidikan Menengah Kejuruan menerapkan kebijakan strategi implementasi revitalisasi SMK alah satunya Program Keahlian Agribisnis Pengolahan Hasil Pertanian. Tujuan Revitalisasi SMK adalah untuk memujudkan link and Match sekolah dengan Dunia Usaha/Industri (DuDi) untuk mengurangi/ menghilangkan kesenjangan antara pendidikan kejuruan dengan kebutuhan DuDi sehingga meningkatkan 
kebekerjaan lulusan SMK. Tiga kegiatan penting dalam strategi implementasi revitalisasi SMK adalah pengembangan kurikulum berbasis industri, teaching factory, dan sertifikasi kompetensi lulusan. Pengembangan kurikulum berbasis industri dilakukan dengan melakukan penyelarasan antara kurikulum di SMK dengan kebutuhan DuDi dengan pelaksanaa pembelajaran melalui sistem blok. Guna mendukung pembelajaran berbasis industri, SMK mengembagkan teaching factory yang merupakan unit produksi yang menyerupai pabrik / tempat produksi barang dan jasa yang digunakan dalam proses pembelajaran. Uji sertifikasi profesi diberlakukan untuk mengukur kemampuan peserta didik level KKNI 2 untuk SMK 3 tahun dan level KKNI 3 untuk SMK 4 tahun. Pelaksanaan uji sertifikasi dilakukan oleh LSP di SMK mengacu pada skema sertifikasi profesi KKNI, unit kompetensi atau klaster yang ditetapkan BNSP.

\section{Ucapan terima kasih}

Ucapan terima kasih disampaikan kepada Kepala Pusat dan Kepala Bidang Fasilitasi Peningkatan Kompetensi pada Pusat Pengembangan dan Pemberdayaan Pendidik dan Tenaga Kependidikan Cianjur yang memberi kesempatan untuk mengikuti seminar Nasional Agroindustri 2018 dengan tema Inovasi agroindustri menghadapi era industri 4.0

\section{DAFTAR PUSTAKA}

BPS. 2016. Ketenagakerjaan. Jakarta: Badan Pusat Statistik

Direktorat Pembinaan SMK 2017, Strategi Implementasi Reviasliasi SMK. Direktorat Jenderal Pendidikan Dasar dan Menengah Kementerian Pendidikan Dan Kebudayaan 2017.

GIZ. 2015. Guidelines Designing TVET Measures. Germany.

ILO. 2015. ASEAN Community 2015: Managing intengarion for Better Jobs and Shared Poverty. Bangkok

Kementerian Pendidikan Dan Kebudayaan 2016. Revitalisasi Pendidikan Vokasi Kementerian Pendidikan Dan Kebudayaan. Kementerian Pendidikan Dan Kebudayaan. Jakarta.

Peraturan Dirjen 07/D.D5/KK/2018 tentang Struktur Kurikulum Sekolah Menengah Kejuruan (SMK)/ Madrasah Aliyah Kejuruan (MAK)

Republik Indonesia 2016. Inpres No.9 tentang Revitalisasi SMK

Republik Indonesia 2003. Undang-undang Nomor 20 tentang Sistem Pendidikan Nasional. 